\title{
Evaluation of clinical outcomes in neuropathic pain with combinations of anti-neuropathic drugs
}

\author{
Shaik A. Pasha ${ }^{1 *}$, S. Vidyadhara ${ }^{2}$, M. Raghava Kalyan ${ }^{3}$, Lakshmi Banu Sri ${ }^{3}$, N. Keerthi ${ }^{3}$, \\ A. Harshitha ${ }^{3}$, K. Sravani ${ }^{3}$, Ramineni Haribabu ${ }^{3}$
}

\begin{abstract}
${ }^{1}$ Department of Neurology, NRI Medical College and General Hospital, Chinakakani, Guntur, Andhra Pradesh, India ${ }^{2}$ Department of Pharmaceutics, ${ }^{3}$ Department of Pharmacy Practice, Chebrolu Hanumaiah Institute of Pharmaceutical Sciences, Chowdavaram, Guntur, Andhra Pradesh, India
\end{abstract}

Received: 26 November 2019

Revised: 25 January 2020

Accepted: 29 January 2020

\section{*Correspondence:}

Dr. Shaik A. Pasha,

Email: afsarpasha@gmail.com

Copyright: (c) the author(s), publisher and licensee Medip Academy. This is an open-access article distributed under the terms of the Creative Commons Attribution Non-Commercial License, which permits unrestricted non-commercial use, distribution, and reproduction in any medium, provided the original work is properly cited.

\section{ABSTRACT}

Background: Much of the pharmacological treatment modalities especially individual drugs for treating neuropathic pain have unwanted side effects, multiple day to day dosing, modest efficacy of topical treatments, and their local side effects. Combination drug regimen has the advantage of offering relatively better pain relief at lower drug doses and lesser side effects.

Methods: The study was conducted in the Department of Neurology at NRI General Hospital, Guntur. The patients who met the inclusion and exclusion criteria were enrolled and assigned into 3 groups of the study drug combinations. The baseline characteristics and post interventional scores of Toronto Clinical Scoring System (TCSS), visual analogue scale (VAS), Hamilton Anxiety Rating Scale (HAM-A), Hamilton Depression Rating Scale (HAM-D) and Medical outcome of sleep scale (MOS) and were analyzed using t test and mean difference.

Results: A statistically significant reduction in neuropathic pain in all the three groups was found. The mean difference between the baseline and post interventional scores of TCSS and VAS of group I, II and III were 2.97, 2.75 , and $1.97 ; 2.32,1.12$, and 0.95 respectively. There was a statistically significant improvement of HAM-A in all the three groups, HAM-D and MOS sleep scale were found significant only in group II.

Conclusions: The study findings revealed that all the three drug combinations were effective in the management of neuropathic pain with pregabalin and oxcarbazepine combination being better with respect to efficacy and tolerability. Regarding the treatment of depression and sleep disturbances associated with NP pregabalin and duloxetine was more effective.

Keywords: Drug combinations, Neuropathic pain, Toronto clinical scoring systems, Visual analogue scale

\section{INTRODUCTION}

Neuropathic pain (NP) is defined as "pain arising as a direct consequence of any lesion or disease affecting the somatosensory system." ${ }^{1,2}$ Although NP may be an idiopathic process reflecting abnormal sensory processing in the peripheral or central nervous system, it more often appears following physical insult or disease affecting the peripheral or central nervous system. It is likely that chronic peripheral neuropathy may lead to neuroplastic changes and affect the central nervous system. These functional and anatomical changes can exacerbate the overall experience of pain. As the changes become more chronic, co-morbid conditions such as sleep disorders, anxiety and depression can accompany the chronic pain, and further complicate treatment. 
It is estimated to afflict millions of people worldwide, although precise figures are not available. ${ }^{3-5}$ Moreover, the prevalence of NP conditions is difficult to establish. There are many confounding factors that may lead to under-reporting of NP. In primary medical care settings, the prevalence has been reported to be between 2 and $11 \%{ }^{6,7}$ Studies have focused on specific NP conditions, secondary to other pathological conditions. Painful diabetic neuropathy is one of the most common causes of chronic pain. It has been shown that the about $26 \%$ of patients with type 2 diabetes can experience neuropathy. ${ }^{8}$ Cancer patients indicate a prevalence of $19-39 \%$. About $1 \%$ and $37 \%$ of chronic low back pain patients may have a neuropathic component related to it. ${ }^{9,10}$ Even with high prevalence in chronic conditions, the overall numbers of NP conditions tends to be small. One of the reasons is the lack of identification, diagnosis, and treatment. There is no standard approach between health care providers for NP.

Adverse physical, psychological, and economic consequences associated with NP lead to poor quality of life. Burden of NP in developing countries like India is colossal. Various International guidelines provide effective approaches to diagnose and manage NP. However, differences in the genetic makeup of Indian population can result in subtle differences in clinical response, considering their low body weight, drug metabolism ability, and pain perception. Similarly, treatment-related adverse effects may also vary. Practice of Indian physicians may also differ for choice of drugs based on their availability and affordability.

Much of the pharmacological treatments modalities especially individual drugs for treating NP have unwanted side effects, multiple day-to-day dosing, modest efficacy of topical treatments, and their local side effects. The practitioners have to assess a delicate balance of pain relief and adverse events, which further emphasizes the need for a combination drug therapy. Combination drug regimen has the advantage of offering relatively better pain relief at lower drug doses and lesser side effects. ${ }^{11,12}$ Hence the objective of the study was to evaluate the efficacy and safety profiles of different combinations of anti-neuropathic agents using the starting doses of the drugs.

\section{METHODS}

The study has been conducted in Department of Neurology at NRI General and Super specialty Hospital located at Guntur, Andhra Pradesh, India. This is a prospective observational study, which assessed the clinical outcomes of different drug combinations in patients with neuropathic pain and is being treated with different combinations of anti-neuropathic agents. The study was approved by the Institutional Human Ethical Committee of Chebrolu Hanumaiah Institute of Pharmaceutical Sciences, Guntur, Andhra Pradesh, India.
The study was initiated after obtaining the approval from the Institutional Human Ethics Committee of Chebrolu Hanumaiah Institute of Pharmaceutical Sciences, Guntur. All the patients who were presented to the Department of Neurology with the diagnosis of neuropathic pain during the period July 2018 to February 2019 were considered for study sample (which included both central and peripheral neuropathic pain) and were enrolled basing on the inclusion and exclusion criteria with a prior informed consent from the patient.

The patients who met with the following criteria were Included for the study: patients newly diagnosed with neuropathic pain, drug naïve patients, those who were aged $\geq 18$ years and patients who were prescribed with the drug combinations intended for the study, whereas patients who were pregnant and lactating, those already under the therapy of any drug used in the study, those patients who underwent renal transplant or currently on dialysis, those with known psychiatric illness, patients who were not willing to participate in the study and those who underwent amputation or currently on antibiotic regimens for diabetic foot were excluded.

Out of all the patients who attended the outpatient department of neurology and diagnosed with neuropathy, a total of 125 patients met the inclusion criteria were enrolled into the study and were divided into 3 groups based on the drug combination prescribed as per physician's choice. Out of 125 patients who were enrolled for the study, 43 patients were prescribed with oxcarbazepine and pregabalin (group I), 41 with duloxetine and pregabalin (group II), and 40 with amitriptyline and gabapentin (group III). A total of 6 members were excluded from the study due to the lack of complete data and follow up. Out of the 6 members 2 members belonged to group I, 1 from group II and 3 from group III.

The details regarding patient's demographics such as age, gender, patient ID, weight and any co-morbid conditions, if present were entered into the excel sheet. Other details such as diabetic condition along with their blood glucose levels which included RBS, PPBS, and FBS status prior to the treatment and after the treatment were also included in case of diabetic population.

The intensity and severity of neuropathy was assessed by administering scales such as Toronto Clinical Scoring System (TCSS) 13 which includes 13 items related to the evaluation of sensory and motor symptoms with a max score of 19, visual analogue scale (VAS) on a scale of 10 $\mathrm{cm}$ for pain severity, autonomic symptom scale for the analysis of autonomic neuropathy were evaluated for each patient and scored accordingly. ${ }^{14}$ Hamilton Anxiety Rating Scale (HAM-A), Hamilton Depression Rating scale (HAM-D) and Medical Outcomes of Sleep Scale (MOS scale) were applied before initiation of the treatment and after the completion of the treatment for the evaluation of alterations in the psychologic effects of 
neuropathic pain and also as a measurement of side effects of the anti-neuropathic agents. ${ }^{15-17}$ Nerve conduction studies were performed in some patients as per the need for evaluation of neuropathy.

The patients received pregabalin $75 \mathrm{mg}$ OD and oxcarbazepine $150 \mathrm{mg}$ BD in group I, pregabalin $75 \mathrm{mg}$ OD and duloxetine $20 \mathrm{mg}$ OD in group II and gabapentin $100 \mathrm{mg}$ OD and amitriptyline $10 \mathrm{mg}$ OD in group III respectively. The scales which were used to evaluate Neuropathy were administered twice to each patient. A base line score was taken before the administration of study drugs and post treatment scores were obtained after a period of four weeks of drug therapy. Using the difference in means of the pre and post scores, the effectiveness and safety of the combinational therapy were evaluated.

\section{Statistical analysis}

The data was analyzed using students t test, paired t test and mean difference of post interventional scores at a significance of $5 \%(\mathrm{p}<0.05)$ in which significance of interventional treatment was determined.

\section{RESULTS}

A total of 125 patients were recruited in the study and 119 patients participated and followed during the follow up period. Due to lack of complete data and non-follow-up, 6 members were excluded from the study. Patient's study sample after complete follow-up was evaluated for the following parameters. Based on the clinical diagnosis the distribution of sample of the study was divided into central neuropathic pain and peripheral neuropathic pain as illustrated in the following Table 1 which showed no statistically significant difference.

Table 1: Distribution of sample population based on diagnosis.

\begin{tabular}{|lll|}
\hline Groups & Central NP (\%) & Peripheral NP (\%) \\
\hline I & $27(35)$ & $14(33.3)$ \\
\hline II & $25(32.5)$ & $15(35.8)$ \\
\hline III & $25(32.5)$ & $13(30.9)$ \\
\hline
\end{tabular}

There was a statistically significant reduction in the post interventional scores of TCSS in all the three groups which indicates that all the three drug combinations were found effective in the management of the neuropathic pain. The mean differences of TCSS in group I, II and II were $2.97,2.75$ and 1.97 respectively. With regard to the mean difference between the baseline and post scores group I i.e. the drug combination of pregabalin and oxcarbazepine was found more effective in the management of NP followed by group II (pregabalin and duloxetine). The statistical data of the TCSS in Group I, II and III were described in the following (Table 2).

The VAS scores showed a statistically significant improvement in the pain associated with the neuropathy in all the groups with a highly significant change in group I. The mean differences of the baseline and post interventional scores of VAS in group I, II and III were $2.32,1.12$ and 0.95 respectively. With regard to the VAS scores there was a greater reduction in the pain scores in group I achieved by the drug combination pregabalin and oxcarbazepine. The detailed view of the scores of VAS was described below in the (Table 3 ).

Table 2: Comparisons of baseline scores and post-interventional scores of TCSS for group I, II and III.

\begin{tabular}{|llllll|} 
Scales & Groups & $\begin{array}{l}\text { Base line scores } \\
(\text { mean } \pm \text { SD })\end{array}$ & $\begin{array}{l}\text { Post interventional scores } \\
(\text { mean } \pm \text { SD })\end{array}$ & Mean difference & P value \\
\hline \multirow{2}{*}{ TCSS } & I & $10.97 \pm 3.43$ & $8 \pm 3.06$ & 2.97 & 0.0001 \\
\cline { 2 - 7 } & II & $9.7 \pm 3.09$ & $6.95 \pm 3.02$ & 2.75 & 0.0001 \\
\hline
\end{tabular}

TCSS- Toronto clinical scoring system.

Table 3: Comparisons of baseline scores and post-interventional score of VAS for group I, II and III.

\begin{tabular}{|llllll|} 
Scales & Groups & $\begin{array}{l}\text { Base line scores } \\
(\text { mean } \pm \text { SD })\end{array}$ & $\begin{array}{l}\text { Post interventional scores } \\
(\text { mean } \pm \text { SD) }\end{array}$ & Mean difference & P value \\
\hline \multirow{3}{*}{ VAS } & I & $4.53 \pm 1.56$ & $2.21 \pm 1.35$ & 2.32 & $5.34 \mathrm{E}-10$ \\
\cline { 2 - 7 } & II & $3.62 \pm 1.56$ & $2.5 \pm 1.62$ & 1.12 & 0.002 \\
\hline
\end{tabular}

VAS- Visual analogue scale.

The HAM-A, HAM-D and MOS sleep scale were analysed with an intention to the other symptoms that are associated with the NP, and also as a measure of adverse effects related to the drugs intended for the study.
The baseline and the post interventional scores of the HAM-A, HAM-D and MOS sleep scale were described in the following (Table 4). The mean difference of the HAM-A in group I, II and III were 3.03, 2.05 and 1.58. 
Table 4: Comparison of baseline scores and post interventional scores of HAM-A, HAM-D, MOS sleep scale in all the three groups.

\begin{tabular}{|llllll|} 
Scales & Groups & $\begin{array}{l}\text { Baseline score } \\
(\text { mean } \pm \text { SD })\end{array}$ & $\begin{array}{l}\text { Post interventional score } \\
(\text { mean } \pm \text { SD) }\end{array}$ & $\begin{array}{l}\text { Mean } \\
\text { difference }\end{array}$ & $\begin{array}{l}\text { P } \\
\text { value }\end{array}$ \\
\hline \multirow{3}{*}{ HAM-A } & I & $11.17 \pm 7.52$ & $8.14 \pm 5.55$ & 3.03 & 0.044 \\
\hline \multirow{3}{*}{ HAM-D } & II & $7.92 \pm 3.72$ & $5.87 \pm 3.48$ & 2.05 & 0.014 \\
\cline { 2 - 6 } & III & $8.43 \pm 3.03$ & $6.89 \pm 2.58$ & 1.58 & 0.018 \\
\hline \multirow{2}{*}{$\begin{array}{l}\text { MOS sleep } \\
\text { scale }\end{array}$} & II & $8.92 \pm 6.23$ & $7.12 \pm 5.66$ & 1.80 & 1.790 \\
\cline { 2 - 6 } & III & $7.7 \pm 3.41$ & $5.25 \pm 2.87$ & 2.45 & 0.0009 \\
\cline { 2 - 6 } & II & $6.31 \pm 3.17$ & $5.68 \pm 3.07$ & -1.49 & 0.388 \\
\hline
\end{tabular}

HAM-A: Hamilton anxiety rating scale, HAM-D: Hamilton Depression rating scale, MOS - Medical outcome sleep scale.

There was a statistically significant change in the baseline and post interventional scores of HAM-A in all the three groups I, II and III indicating that all the three drug combinations can be used for the treatment of the anxiety associated with NP; whereas HAM-D showed statistically significant difference only in group II. While comparison of MOS sleeps scale there was a proven statistical significance only in group II. With regard to the treatment of the depression and sleep disturbances associated with the NP group II was found significant indicating pregabalin and duloxetine was more effective in the management of the depression and the sleep disturbances associated with NP.

\section{DISCUSSION}

Neuropathic pain is a common component of a range of pain states that are most commonly associated with some form of neural damage. ${ }^{18,19} \mathrm{NP}$ constitutes a major painrelated disorder, which is often under-diagnosed and undertreated despite the availability of drugs with proven efficacy. Besides the significant burden of NP, it is considered to be a complex condition and acknowledged as being difficult to treat. ${ }^{20}$ Cure and elimination of neuropathic pain are unlikely and thus neuropathic pain frequently has a profound negative impact on quality of life. $^{20-22}$

The principal aim of care in treating patients with neuropathic pain is to improve their quality of life by achieving meaningful pain relief and improving physical function while minimising adverse drug effects. ${ }^{23}$

In this prospective study combination therapy involving pregabalin and oxcarbazepine was effective in controlling neuropathic pain of both central and peripheral origin and the next alternative drug combo is pregabalin and duloxetine. Further improvements in NP severity were accomplished in group I and II patients, although those patients the former may have had a relatively better response. Not only the individual, but the family and the society as a whole are affected from the direct and indirect consequences of NP. ${ }^{24,25} \mathrm{NP}$ severity is associated with loss of productivity and needs more visits to the physician and higher number of medications for treatment. ${ }^{24}$ The economic burden of NP is a significant concern in developing countries like India.

Our study found that there was a significant decrease in the post interventional scores of TCSS of group I when compared to the baseline score, with a mean difference of 2.97. The mean base line score and post interventional VAS scores of group I were 4.53 and 2.21 respectively. It was found that there was a significant decrease in the baseline and post interventional scores of VAS of group I with a mean difference of 2.32. The post interventional VAS score of our study is $2.21 \pm 1.35$ which is similar to that study conducted by Hahm et al $(2.1 \pm 0.6){ }^{26}$ Pregabalin is increasingly used instead of gabapentin for the treatment of neuropathic pain because it potentially has higher potency and fewer side-effects. ${ }^{27,28} \mathrm{~A}$ recent meta-analysis revealed the efficacy of pregabalin in central neuropathic pain and fibromyalgia. ${ }^{29}$ Additionally evidence suggests that carbamazepine and pregabalin act synergistically to treat allodynia. ${ }^{26}$

The mean baseline and post interventional scores of the TCSS in group II were 9.7 and 6.95 with a mean difference of 2.75. The mean base line score and post interventional score of group II were 4.53 and 2.21 along with mean difference of 1.12 respectively which is similar to that of the study conducted by Tesafye et al in which the mean difference is $1.2 .^{30}$ It was found that there was a significant decrease in the baseline and post interventional scores of VAS of group II. Our study revealed that there was a significant decrease in the anxiety related symptoms with mean differences of 2.05 in group II through the comparison of baseline and post interventional scores of HAM-A.

Through the analysis of the baseline and post interventional scores along with mean differences of 2.45 it was found that group II drug combination showed significant decrease in the depression related symptoms associated with the neuropathic pain. This is in line with that of Tannenberg et al who found that combination 
therapy with duloxetine plus pregabalin was associated with significantly greater reduction in pain $(\mathrm{p} \leq 0.05){ }^{31}$

The mean baseline and post interventional score of TCSS were 11.97 and 10 with a mean difference of 1.97 which shows a significant reduction in the pain intensity. The mean base line score and post interventional score of group I were 4.53 and 2.21 respectively. It was found that there was a significant decrease in the baseline and post interventional scores of VAS of group III with mean differences of 0.95 . The mean difference of our pain score 1.0 is in low range when compared with study conducted by Gilron et al with mean difference of 3.12. In their randomized controlled study Morello et al compared the baseline pain scores in 21 patients and found that there was a statistically significant difference in pain score reduction in patients treated with both gabapentin and amitriptyline $(\mathrm{p}<0.001) .{ }^{32,33}$

The main limitations are the inability to perform head-tohead comparisons for first-time therapy, and the unblinded status of patient assessments. Next, there is no optimal control group to compare with given the absence of placebo. It must consider that patients referred to and followed at our tertiary care clinic may have not been representative of the general population of patients with NP.

Management of patients with neuropathic pain often requires long-term engagement. Early investigation to establish the underlying cause and initiate appropriate pain relief is critical to avoid transition to a chronic pain state. Combination therapy, that is, the combination of different pharmacological treatments, has not been a part of guidelines until recently. The idea of combination therapy using two drugs with different mechanisms of action is of great interest, as it is widely acknowledged that many patients have insufficient pain relief on monotherapy with the currently used drugs. ${ }^{34}$ The combination of pregabalin/gabapentin and TCAs was the best documented and experts had good clinical experience with this combination in the management of NP. The combination pregabalin/gabapentin and duloxetine in particular was also reasonably well documented with good clinical experience and fewer side effects than highdose monotherapy. ${ }^{35}$ The present study findings concur with these observations.

\section{CONCLUSION}

The study findings reveal that all the three drug combinations were effective in the management of neuropathic pain with pregabalin and oxcarbazepine combination being better with respect to efficacy and tolerability while the next better combination was pregabalin and duloxetine. Regarding the treatment of depression and sleep disturbances associated with NP, pregabalin and duloxetine combination was more effective and hence can be considered in the management of depression and sleep disturbances among the patients with neuropathic pain.

Funding: No funding sources

Conflict of interest: None declared

Ethical approval: The study was approved by the Institutional Ethics Committee

\section{REFERENCES}

1. Haanpää M, Attal N, Backonja M, Baron R, Bennett M, Bouhassira D, et al. NeuPSIG guidelines on neuropathic pain assessment. PAIN®. 2011;152(1):14-27.

2. Treede RD, Jensen TS, Campbell JN, Cruccu G, Dostrovsky J, Griffin J, et al. Neuropathic pain: redefinition and a grading system for clinical and research purposes. Neurol. 2008;70(18):1630-5.

3. Hall GC, Carroll D, Parry D, McQuay HJ. Epidemiology and treatment of neuropathic pain: the UK primary care perspective. Pain. 2006;122(1-2):15662.

4. Harrison RA, Field TS. Post stroke pain: identification, assessment, and therapy. Cerebrovas Dis. 2015;39(34):190-201.

5. Westaway KP, Alderman CP, Frank OR, Husband AJ, Rowett D, Le Blanc T. Optimising therapy for patients with neuropathic pain. J Pharma Pract Res. 2014;44(1):44-7.

6. Clark JD. Chronic pain prevalence and analgesic prescribing in a general medical population. J Pain symptom management. 2002;23(2):131-7.

7. Koleva D, Krulichova I, Bertolini G, Caimi V, Garattini L. Pain in primary care: an Italian survey. Europ $\mathrm{J}$ Public Health. 2005;15(5):475-9.

8. Davies M, Brophy S, Williams R, Taylor A. The prevalence, severity, and impact of painful diabetic peripheral neuropathy in type 2 diabetes. Diabetes Care. 2006;29(7):1518-22.

9. Bennett MI, Rayment C, Hjermstad M, Aass N, Caraceni A, Kaasa S. Prevalence and aetiology of neuropathic pain in cancer patients: a systematic review. Pain. 2012;153(2):359-65.

10. Freynhagen R, Baron R, Tölle T, Stemmler E, Gockel $\mathrm{U}$, Stevens M, et al. Screening of neuropathic pain components in patients with chronic back pain associated with nerve root compression: a prospective observational pilot study (MIPORT). Curr Med Res Opinion. 2006;22(3):529-37.

11. Pollmann W, Feneberg W. Current management of pain associated with multiple sclerosis. CNS Drugs. 2008;22(4):291-324.

12. Zin CS, Nissen LM, Smith MT, O'Callaghan JP, Moore BJ. An update on the pharmacological management of post-herpetic neuralgia and painful diabetic neuropathy. CNS Drugs. 2008;22(5):417-42.

13. Bril V, Perkins BA. Validation of the Toronto Clinical Scoring System for diabetic polyneuropathy. Diabetes Care. 2002;25(11):2048-52.

14. Hawker GA, Mian S, Kendzerska $T$, French $M$. Measures of adult pain: Visual analog scale for pain (vas pain), numeric rating scale for pain (nrs pain), mcgill pain questionnaire (mpq), short-form mcgill pain questionnaire (sf-mpq), chronic pain grade scale (cpgs), 
short form-36 bodily pain scale (sf-36 bps), and measure of intermittent and constant osteoarthritis pain (icoap). Arthr Care Res. 2011;63(11):240-52.

15. Hamilton $\mathrm{M}$. The assessment of anxiety states by rating. Brit J Med Psychol. 1959;32:50-5.

16. Hamilton. M, Hamilton Depression Rating Scale (HAM- D). J Neurol, Neurosurg, Psychiatr. 1960;23:5662.

17. Hays RD, Martin SA, Sesti AM, Spritzer KL. Psychometric properties of the medical outcomes study sleep measure. Sleep Med. 2005;6(1):41-4.

18. Cohen SP, Mao J. Neuropathic pain: mechanisms and their clinical implications. BMJ. 2014;348:7656.

19. Costigan M, Scholz J, Woolf CJ. Neuropathic pain: a maladaptive response of the nervous system to damage. Annual Rev Neurosci. 2009;32:1-32.

20. Dworkin RH, O'connor AB, Backonja M, Farrar JT, Finnerup NB, Jensen TS, et al. Pharmacologic management of neuropathic pain: evidence-based recommendations. Pain. 2007;132(3):237-51.

21. Jensen MP, Chodroff MJ, Dworkin RH. The impact of neuropathic pain on health-related quality of life: review and implications. Neurol. 2007;68(15):1178-82.

22. McCarberg BH, Nicholson BD, Todd KH, Palmer T, Penles L. The impact of pain on quality of life and the unmet needs of pain management: results from pain sufferers and physicians participating in an Internet survey. Am J Therapeut. 2008;15(4):312-20.

23. Turk DC, Wilson HD, Cahana A. Treatment of chronic non-cancer pain. Lancet. 2011;377(9784):2226-35.

24. Schaefer C, Sadosky A, Mann R, Daniel S, Parsons B, Tuchman $\mathrm{M}$, et al. Pain severity and the economic burden of neuropathic pain in the United States: BEAT Neuropathic Pain Observational Study. Clinico Economics Outcomes Res: CEOR. 2014;6:483.

25. McCarberg BH, Billington R. Consequences of neuropathic pain: quality-of-life issues and associated costs. Am J Manag Care. 2006;12(9):263-8.

26. Hahm T, Ahn H, Ryu S, Gwak M, Choi S, Kim J, et al. Combined carbamazepine and pregabalin therapy in a rat model of neuropathic pain. Brit $\mathbf{J}$ Anaesthesia. 2012;109(6):968-74.

27. Taylor CP, Angelotti T, Fauman E. Pharmacology and mechanism of action of pregabalin: the calcium channel $\alpha 2-\delta$ (alpha2-delta) subunit as a target for antiepileptic drug discovery. Epilepsy Res. 2007;73(2):137-50.
28. Tremont-Lukats IW, Megeff C, Backonja MM. Anticonvulsants for neuropathic pain syndromes. Drugs. 2000;60(5):1029-52.

29. Wiffen PJ, Derry S, Moore RA, Aldington D, Cole P, Rice AS, et al. Antiepileptic drugs for neuropathic pain and fibromyalgia-an overview of Cochrane reviews. Cochrane Database Systematic Rev. 2013(11).

30. Tesfaye S, Wilhelm S, Lledo A, Schacht A, Tölle T, Bouhassira D, et al. Duloxetine and pregabalin: highdose monotherapy or their combination? The "COMBODN study"-a multinational, randomized, double-blind, parallel-group study in patients with diabetic peripheral neuropathic pain. Pain. 2013;154(12):2616-25.

31. Tanenberg RJ, Clemow DB, Giaconia JM, Risser RC. Duloxetine Compared with Pregabalin for Diabetic Peripheral Neuropathic Pain Management in Patients with Suboptimal Pain Response to Gabapentin and Treated with or without Antidepressants: A Post Hoc Analysis. Pain Pract. 2014;14(7):640-8.

32. Gilron I, Bailey JM, Tu D, Holden RR, Jackson AC, Houlden RL. Nortriptyline and gabapentin, alone and in combination for neuropathic pain: a double-blind, randomised controlled crossover trial. Lancet. 2009;374(9697):1252-61.

33. Morello CM, Leckband SG, Stoner CP, Moorhouse DF, Sahagian GA. Randomized double-blind study comparing the efficacy of gabapentin with amitriptyline on diabetic peripheral neuropathy pain. Arch Int Med. 1999;159(16):1931-7.

34. Chaparro LE, Wiffen PJ, Moore RA, Gilron I. Combination pharmacotherapy for the treatment of neuropathic pain in adults. Cochrane Database Systematic Rev. 2012; 7.

35. Holbech JV, Jung A, Jonsson T, Wanning M, Bredahl C, Bach FW. Combination treatment of neuropathic pain: Danish expert recommendations based on a Delphi process. J Pain Res. 2017;10:1467.

Cite this article as: Pasha SA, Vidyadhara $S$, Kalyan MR, Sri LB, Keerthi N, Harshitha A, et al. Evaluation of clinical outcomes in neuropathic pain with combinations of anti-neuropathic drugs. Int $\mathbf{J}$ Basic Clin Pharmacol 2020;9:430-5. 